\title{
Investigation of the reactivity of palladium(0) complexes with nitroso compounds: relevance to the palladium-phenanthroline- catalysed carbonylation reactions of nitroarenes
}

\author{
Emma Gallo a, Fabio Ragaini ${ }^{a}$, Sergio Cenini ${ }^{\mathrm{a}, *}$, Francesco Demartin ${ }^{\mathrm{b}}$ \\ a Dipartimento di Chimica Inorganica, Metallorganica e Analitica and CNR Center, via G. Venezian 21-20133, Milan, Italy \\ ${ }^{\mathrm{b}}$ Dipartimento di Chimica Strutturale e Stereochimica Inorganica and CNR Center, via G. Venezian 21-20133, Milan, Italy
}

Received 12 March 1999; received in revised form 5 May 1999

\begin{abstract}
The electron transfer reaction between palladium(0) complexes and RNO compounds afforded different palladium species depending on the aromatic or aliphatic nature of $\mathrm{R}$. When $\mathrm{R}=\mathrm{Ph}$ a paramagnetic palladium complex $\mathbf{1}$ was isolated, whereas if $\mathrm{R}=\mathrm{Bu}^{t}$ the palladium enolate complex $\mathbf{2}$ was the unexpected reaction product. Complex $\mathbf{1}$ reacted with methanol and $\mathrm{CO}$ to yield $\mathrm{Pd}($ phen $)\left\{\mathrm{C}(\mathrm{O}) \mathrm{OCH}_{3}\right\}_{2}$ 3, which was characterised by single-crystal X-ray structure determination. Compound $\mathbf{3}$ is a probable intermediate in the reductive carbonylation reaction of organic nitro compounds catalysed by palladium complexes. Nitrobenzene is in fact carbonylated to $\mathrm{PhNHCO}_{2} \mathrm{Me}$, by using 3 as a very efficient catalyst. (C) 1999 Elsevier Science S.A. All rights reserved.
\end{abstract}

Keywords: Palladium; Phenanthroline; Carbonylation reactions; Nitroarenes; X-ray structure

\section{Introduction}

The reductive carbonylation of nitro compounds is a field of great interest and much effort has been devoted to clarify the mechanisms of several catalytic cycles [1]. Palladium phenanthroline complexes $[2,3,20]$ are the most active catalysts for this class of reactions. A probable intermediate in the catalytic cycle, the metallacycle $(\mathrm{N}-\mathrm{N}) \mathrm{PdC}(\mathrm{O}) \mathrm{ON}(\mathrm{Ar}) \mathrm{C}(\mathrm{O})$, has been obtained from the reaction between $\mathrm{Pd}($ phen $)(\mathrm{OAc})_{2}$ (phen $=$ 1,10-phenanthroline) and nitrobenzene, under CO pressure [3], and recently characterised by X-ray structure determination [4]. It is believed that the formation of this intermediate is the result of a transient palladium(0) species but neither this last complex, nor any of the intermediates proposed for the reaction leading to the isolated metallacycles, could even be observed by using nitroarenes as reagents. The reductive carbonylation of nitro compounds occurs through a deoxygenation reaction and the formation of nitrosoarene-metal

\footnotetext{
* Corresponding author. Tel.: +39-2-2364512; fax: + 39-22362748 .

E-mail address: scenini@csmtbo.mi.cnr.it (S. Cenini)
}

complexes [5]. Therefore we reasoned that the investigation of the reactivity of $\operatorname{Pd}(0)$ complexes towards nitroso compounds might shed some light on the mechanism of these reactions.

\section{Results and discussion}

First we reacted $\operatorname{Pd}(\mathrm{phen})(\mathrm{pbq}) \quad(\mathrm{pbq}=p$-benzoquinone) [6], a source of ' $P d(0)($ phen)', with different amounts of nitrosobenzene and in different solvents (THF, diglyme, methanol). Invariably an insoluble green paramagnetic product $\mathbf{1}$, was obtained. Complex 1 was the only isolated product even when $\operatorname{Pd}($ phen $)(\mathrm{pbq})$ was replaced by $\operatorname{Pd}(\mathrm{phen})(\mathrm{dba})(\mathrm{dba}=$ dibenzylidene acetone) as starting material. The last complex was generated in situ by reaction of $\mathrm{Pd}_{2}(\mathrm{dba})_{3} \cdot \mathrm{CHCl}_{3}$ with 1,10-phenanthroline [7] before the addition of PhNO. Based on elemental analysis, the composition $\mathrm{Pd}_{2}(\text { phen })_{2}(\mathrm{PhNO})_{3}$ can be proposed for $\mathbf{1}$, but its insolubility also suggests it to be a polymer.

In addition to that, in the $\mathrm{FAB}^{+}$mass spectrum a parent peak at $\mathrm{M}^{+}=500$ attributable to $\mathrm{Pd}(\mathrm{phen})(\mathrm{PhNO})_{2}$, and peaks corresponding to the loss 
of one and two PhNO groups were observed. The IR spectrum of complex 1 showed a sharp peak at 848 $\mathrm{cm}^{-1}$ that may be attributed to the $v(\mathrm{~N}-\mathrm{O})$ [8] of the $\eta^{2}$-bonded nitroso ligand. Complex 1 showed a broad unresolved EPR signal centred at $3208 \mathrm{G}$ with $g=$ 2.0001. The EPR spectrum did not present any hyperfine structure, although this may in part be due to the fact that we had to perform the analysis in the solid state, given the high insolubility of $\mathbf{1}$, and at room temperature (r.t.). In any case, these magnetic data suggest an electron transfer from palladium(0) to the nitroso ligand to yield a $\mathrm{Pd}$-anionic radical nitroso complex. However, the analytical and spectroscopic data did not allow us to identify the exact structure of 1 and unfortunately, the high insolubility of the product prevented a structural characterisation.

Electron transfer reactions between transition metal complexes and nitroso compounds are quite common [9] due to the spin trapping capacity of this 'non-inno-

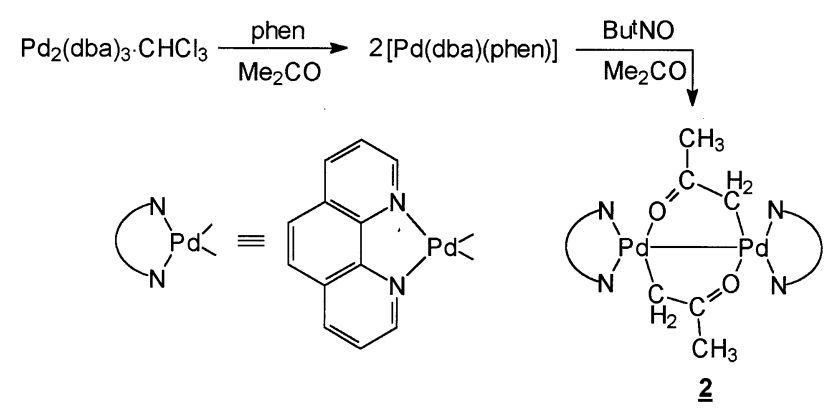

Scheme 1.

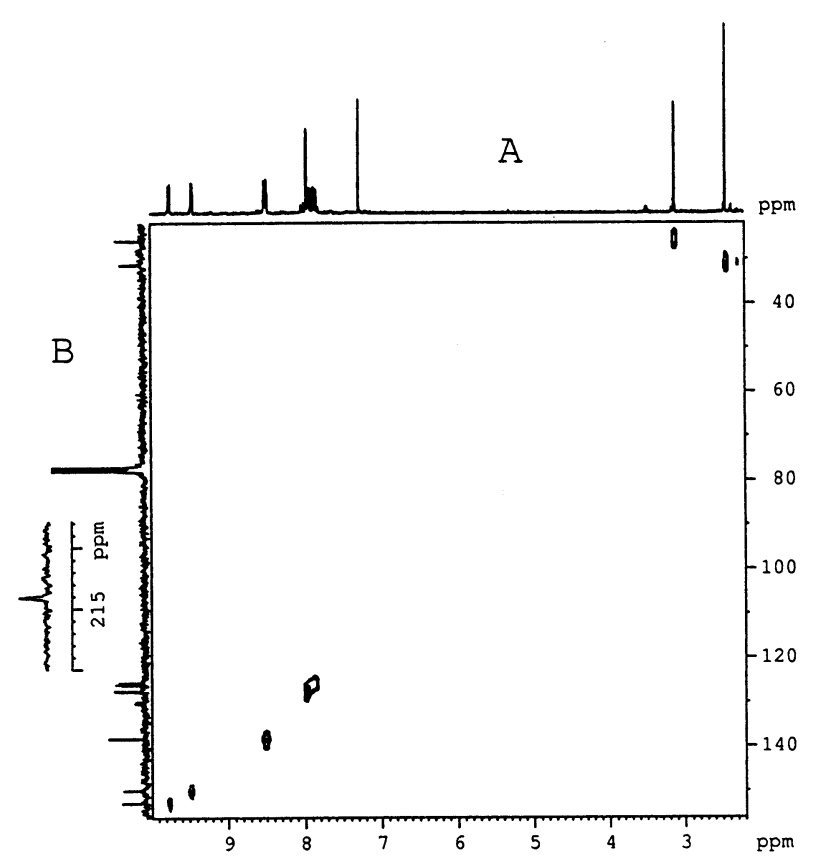

Fig. 1. A two-dimensional heterocorrelate inverse spectroscopy spectrum (HMQC) of complex 2 with: A, ${ }^{1} \mathrm{H}-\mathrm{NMR}$ spectrum; B, ${ }^{13} \mathrm{C}-$ NMR APT spectrum (Attached Proton Test). cent' ligand [10] and the same is true for nitroarenes. The electron transfer from rhodium(-I) [11] and ruthenium(0) [12] complexes to nitro compounds has been followed in situ by EPR but the final organometallic products of these reactions are diamagnetic complexes. On the other hand the reaction between $\operatorname{Pd}($ phen $) \mathrm{L}$ $(\mathrm{L}=\mathrm{pbq}, \mathrm{dba})$ and nitrosobenzene allowed for the isolation of complex $\mathbf{1}$ as a stable paramagnetic compound.

To synthesise a compound more soluble than complex 1, to have more chances for a structural characterisation, $\mathrm{PhNO}$ was replaced by $\mathrm{Bu}^{t} \mathrm{NO}$. However, no reaction was observed between $\mathrm{Pd}(\mathrm{phen})(\mathrm{pbq})$ and $\mathrm{Bu}^{t} \mathrm{NO}$ even after several days at r.t. On the other hand, a reaction occurred when $\mathrm{Bu}^{t} \mathrm{NO}$ was added to an acetone suspension of $\mathrm{Pd}_{2}(\mathrm{dba})_{3} \cdot \mathrm{CHCl}_{3}$ also containing 1,10-phenanthroline, under the same conditions in which the use of PhNO afforded 1. Unexpectedly, a different product $\mathbf{2}$ was obtained for which the structure shown in Scheme 1 can be proposed. If no nitroso compound was added, $\operatorname{Pd}(\mathrm{dba})(\mathrm{phen})$ was isolated in an analytically pure form [7].

The structure of $\mathbf{2}$ is supported by the analytical and spectroscopic data. The peaks at 1633 and $1622 \mathrm{~cm}^{-1}$, observed in the IR spectrum, had been attributed to the carbonyl groups of the enolate fragment. The ${ }^{1} \mathrm{H}-\mathrm{NMR}$ spectrum showed the well-known pattern of the 1,10phenanthroline ligand, with a different chemical shift for the ortho protons of the nitrogen atoms, and two singlets for the $-\mathrm{CH}_{2}-$ and $-\mathrm{CH}_{3}-$ groups of the enolate ligand in the correct integrated ratio. The ${ }^{1} \mathrm{H}$-resonance of the methylene group was observed at $\delta 3.11$ and this resonance indicates that the enolate is C-bound [13]. Moreover the diamagnetic behaviour of the palladium(I) complex 2 requires the presence of a metal-metal bond.

The structure shown in Scheme 1 is also consistent with the ${ }^{13} \mathrm{C}$-NMR APT (attached proton test), the ${ }^{13} \mathrm{C}$-NMR off-resonance and the two-dimensional heterocorrelate inverse spectroscopy (HMQC) experiments (Fig. 1). The ${ }^{15}$ N-NMR INEPT (insensitive nuclei enhancement by polarisation transfer) experiment showed only the 1,10-phenanthroline peak at $-159.9 \mathrm{ppm}$ (nitromethane was used as reference) indicating that no nitrogen atom derived from $\mathrm{Bu}^{t} \mathrm{NO}$ is coordinated to the metal centre.

The parent peak in the $\mathrm{FAB}^{+}$mass spectrum is due to the $\mathrm{Pd}($ phen $)\left(\mathrm{CH}_{2} \mathrm{COCH}_{3}\right)_{2}$ fragment and peaks indicating loss of one or two $-\mathrm{CH}_{2} \mathrm{COCH}_{3}$ fragments were also present, but no peaks corresponding to the loss of $\mathrm{Bu}^{t} \mathrm{NO}$ derived fragments were detected. The molecular peak could not be observed.

Finally, the elemental analysis of complex $\mathbf{2}$ was consistent with the proposed structure, but also showed the presence of one $\mathrm{CHCl}_{3}$ molecule for dimeric unit. The presence of $\mathrm{CHCl}_{3}$ in the compound was also confirmed by a ${ }^{1} \mathrm{H}-\mathrm{NMR}$ spectrum of $\mathbf{2}$ in $\left(\mathrm{CD}_{3}\right)_{2} \mathrm{CO}$. 


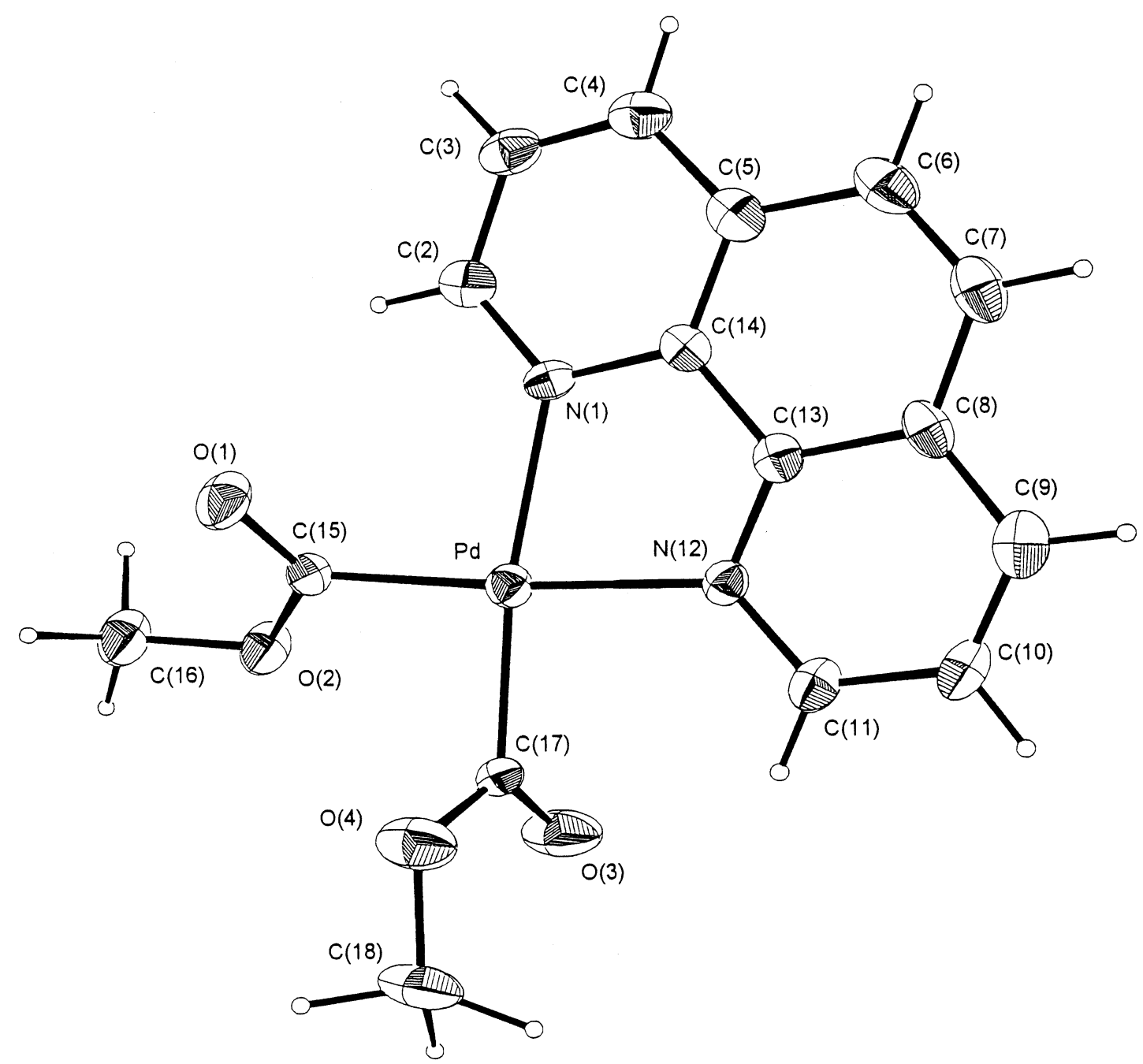

Fig. 2. ORTEP drawing of complex 3. Thermal ellipsoids are drawn at $30 \%$ probability.

The experimental procedures to synthesise complex $\mathbf{1}$ and $\mathbf{2}$ were identical, therefore the different pathways for the two reactions must be due to the different nature of the nitroso compounds. In both cases the first step of the reaction appears to be an electron transfer from the metal center to a nitroso ligand to yield an anionic radical nitroso species and a palladium(I) complex. The anionic radical phenyl nitroso collapses with the palladium-phenanthroline fragment to generate the paramagnetic nitroso palladium complex $\mathbf{1}$, whereas the anionic $t$-butyl nitroso radical is responsible for the deprotonation of the acetone molecule. The resulting enol species coordinates to the palladium center to afford the palladium enolate complex 2 (Scheme 1).

Compound $\mathbf{1}$ is unlikely to be formed during the catalytic carbonylation of nitrobenzene catalysed by palladium-phenanthroline complexes, but mono- or dinuclear complexes in which the extent of reduction of nitrobenzene is the same as the one found in $\mathbf{1}$ may be formed. To investigate this aspect, we reacted 1 with $\mathrm{CH}_{3} \mathrm{OH}$ under $\mathrm{CO}$ pressure under conditions similar to the ones used in catalysis. The complex Pd(phen) $\left\{\mathrm{C}(\mathrm{O}) \mathrm{OCH}_{3}\right\}_{2} 3$ (Fig. 2) was obtained as yellow crystals together with several organic products deriving from the reduction of nitrosobenzene [azoxybenzene $(70 \%)$, methyl phenylcarbamate $(18 \%)$, aniline $(6 \%)$, azobenzene $(2 \%)$, diphenylurea $(2 \%)$ ]. A small amount of nitrobenzene $(2 \%)$, deriving from the disproportionation of nitrosobenzene [14], was also observed.

Complex 3 could also be synthesised either directly from the reaction of $\mathrm{Pd}(\mathrm{phen})$ (pbq) with $\mathrm{PhNO}$ under $\mathrm{CO}$ pressure in methanol or according to a slight modification of the published procedure for the synthesis of $\operatorname{Pd}\left(2,2^{\prime}-\right.$ bipy) $\left\{\mathrm{C}(\mathrm{O}) \mathrm{OCH}_{3}\right\}_{2}[15]$ (we used $\mathrm{NaOCH}_{3}$ instead of $\mathrm{LiOCH}_{3}$ to obtain 3 as a yellow powder in $70 \%$ yield). Very recently Romano and co-workers [16] determined the structure of $\mathbf{3}$ by ab initio X-ray powder diffraction methods. However, we were able to grow crystals of this material suitable for X-ray diffraction and here we report the single-crystal X-ray structure determination for this compound. The molecular structure of $\mathbf{3}$ with the atom labelling scheme adopted is shown in Fig. 2. 
Selected interatomic distances and angles are reported in Table 1. A comparison of our data with those obtained from X-ray powder diffraction [16] shows that there is no significant difference in the geometrical parameters of the molecule obtained with the two techniques. The values are also very close to those of the analogous bonds and angles observed in $\operatorname{Pd}\left(2,2^{\prime}\right.$ bipy) $\left\{\mathrm{C}(\mathrm{O}) \mathrm{OCH}_{3}\right\}_{2}[15]$.

In their studies on the reductive carbonylation of nitroarenes catalysed by $\mathrm{Ru}(\mathrm{CO})_{3}(\mathrm{dppe}) \quad(\mathrm{dppe}=1,2-$ bis(diphenylphosphino)ethane), Gladfelter and coworkers have demonstrated that this ruthenium complex reacts with nitroarenes to initially afford the nitrosoarene complex $\mathrm{Ru}(\mathrm{CO})_{2}(\mathrm{dppe})\left(\eta^{2}\right.$-ArNO) [5]. In the presence of methanol and $\mathrm{CO}$, this complex affords $\mathrm{Ru}(\mathrm{dppe})(\mathrm{CO})_{2}\left\{\mathrm{C}(\mathrm{O}) \mathrm{OCH}_{3}\right\}_{2}$ [17] and aniline. The aniline then attacks the carbomethoxy complex generating an arylisocyanate molecule that is then trapped by excess aniline to generate a diarylurea [18]. Only at a later stage of the catalytic reaction the diarylurea reacts with methanol to afford a methyl arylcarbamate and one equivalent of aniline.

During our studies on the mechanism of the palladium-phenanthroline-catalysed carbonylation of nitroarenes, we discovered that the reaction proceeds through at least three independent pathways, two of which pass through the aniline as an intermediate [19]. By analogy with ruthenium chemistry it may be proposed that complex 3 is an intermediate in one (or both) of the palladium-based catalytic cycles passing through the aniline as an intermediate. Indeed, when

Table 1

Selected interatomic distances $(\AA)$ and angles $\left(^{\circ}\right)$ for $\mathbf{3}$

\begin{tabular}{lrlr}
\hline $\begin{array}{l}\text { Bond length }(\AA) \\
\mathrm{Pd}-\mathrm{N}(1)\end{array}$ & $2.145(4)$ & $\mathrm{Pd}-\mathrm{N}(12)$ & \\
$\mathrm{Pd}-\mathrm{C}(15)$ & $1.975(5)$ & $\mathrm{Pd}-\mathrm{C}(17)$ & $2.117(4)$ \\
$\mathrm{O}(1)-\mathrm{C}(15)$ & $1.206(6)$ & $\mathrm{O}(3)-\mathrm{C}(17)$ & $1.991(5)$ \\
$\mathrm{O}(2)-\mathrm{C}(15)$ & $1.356(6)$ & $\mathrm{O}(4)-\mathrm{C}(17)$ & $1.351(7)$ \\
$\mathrm{O}(2)-\mathrm{C}(16)$ & $1.457(7)$ & $\mathrm{O}(4)-\mathrm{C}(18)$ & $1.442(8)$ \\
Bond angles $\left({ }^{\circ}\right)$ & & & \\
$\mathrm{N}(1)-\mathrm{Pd}-\mathrm{N}(12)$ & $78.4(2)$ & $\mathrm{N}(1)-\mathrm{Pd}-\mathrm{C}(15)$ & $97.2(2)$ \\
$\mathrm{N}(12)-\mathrm{Pd}-\mathrm{C}(17)$ & $95.0(2)$ & $\mathrm{C}(15)-\mathrm{Pd}-\mathrm{C}(17)$ & $89.9(2)$ \\
$\mathrm{N}(1)-\mathrm{Pd}-\mathrm{C}(17)$ & $172.3(2)$ & $\mathrm{N}(12)-\mathrm{Pd}-\mathrm{C}(15)$ & $171.8(2)$ \\
\hline
\end{tabular}

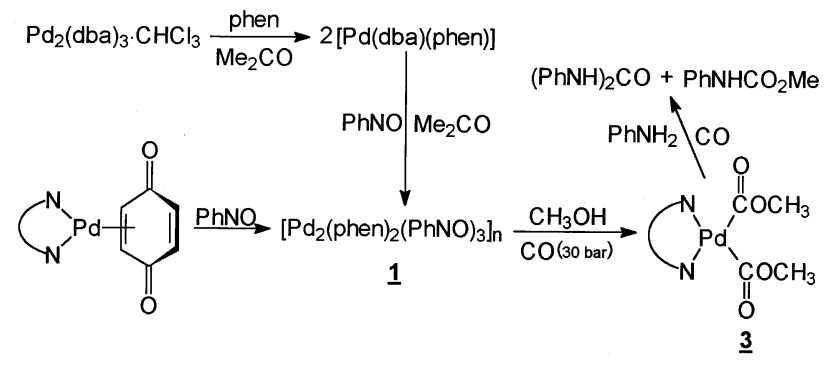

Scheme 2.
$\mathrm{Pd}($ phen $)\left\{\mathrm{C}(\mathrm{O}) \mathrm{OCH}_{3}\right\}_{2} 3$ was reacted with aniline in $\mathrm{CH}_{3} \mathrm{OH}$ and under $\mathrm{CO}$ atmosphere diphenylurea was obtained with methyl phenyl carbamate in a 95:5 ratio (by GC and HPLC analysis), thus supporting an active role of complex 3 in the catalytic reaction (Scheme 2).

To further support this active role of $\mathbf{3}$ we compared the results of a 'classic' catalytic reaction, employing $\left[\mathrm{Pd}(\mathrm{phen})_{2}\right]\left(\mathrm{BF}_{4}\right)_{2}$ as catalyst [20], with one in which 3 was used instead. Both of the reactions were performed in the presence of benzoic acid as promoter [21]. The conversion of nitrobenzene was even higher in the case of $3(27.5 \%$ vs. $21.7 \%)$ while the selectivities were similar in the two cases.

\section{Conclusions}

The aim of this work was to investigate the reaction of palladium( 0 ) complexes with nitroso compounds to improve our knowledge about the mechanism of the catalytic reductive carbonylation of nitro compounds. The isolation of a paramagnetic complex 1 suggests that the first step of the interaction between $\operatorname{Pd}(0)$ and the nitroso species is an electron transfer reaction. Moreover complex $\mathbf{3}$ had already been proposed to be an intermediate in the catalytic cycle [21], and the isolation of this palladium carbomethoxy complex from the reaction of a palladium(0) complex with $\mathrm{PhNO}$ under $\mathrm{CO}$ pressure in methanol supports this proposal. Complex $\mathbf{3}$ is currently under deeper investigation for confirming its importance as intermediate in the reductive carbonylation of nitro compounds.

The different reactivity of $\mathrm{Bu}^{t} \mathrm{NO}$ with respect to the one of PhNO led to the isolation of 2, which is by itself an interesting compound, although it is surely not an intermediate in the carbonylation reactions of organic nitro compounds. The insertion into the $\mathrm{Pd}-\mathrm{C}$ bond of unsaturated molecules might demonstrate a palladiumassisted transfer of the enolate moiety to substrates which would be unlikely to react in a metal-free reaction [22]. On the other hand, it has already been shown [23] that enolate complexes of palladium(II) react with organic electrophilic species to form new $\mathrm{C}-\mathrm{C}$ bonds.

\section{Experimental}

\subsection{General comments}

Unless otherwise specified all reactions were carried out under a purified dinitrogen atmosphere using Schlenk techniques. Solvents were dried and distilled before use by standard methods. Gas chromatographic analyses were performed on a Perkin-Elmer 8420 capillary gas chromatograph equipped with a RTX 5 amine column. HPLC analyses were performed on a Hewlett- 
Packard 1050 instrument equipped with a Purospher ${ }^{\circledR}$ RP-18 e $(5 \mu \mathrm{m})$ column. Infrared spectra were recorded on a Bio Rad FTS-7 FT-IR spectrometer, and NMR spectra using a Brucker 200-AC or a Brucker 300-AC instrument. Elemental analyses and mass spectra were recorded in the analytical laboratories of Milan University. EPR spectra were recorded on a Varian E-109 spectrometer operating at $x$-band frequencies.

\subsection{Reaction of Pd(phen)(pbq) with PhNO}

PhNO (206 mg, $1.92 \mathrm{mmol}$ ) was added to a suspension of Pd(phen)(pbq) (189 mg, $0.48 \mathrm{mmol})$ in THF (20 $\mathrm{ml}$ ). The resulting red suspension was stirred at r.t. for $48 \mathrm{~h}$ to yield a green microcrystalline solid that was collected by filtration, washed with $\mathrm{Et}_{2} \mathrm{O}(10 \mathrm{ml})$, to eliminate the excess $\mathrm{PhNO}$, and dried in vacuo $(70 \%)$. Found $\mathrm{C}, 56.82 ; \mathrm{H}, 3.69 ; \mathrm{N}, 10.85 .\left[\mathrm{C}_{42} \mathrm{H}_{31} \mathrm{~N}_{7} \mathrm{O}_{3} \mathrm{Pd}_{2}\right]_{n}$ requires $\mathrm{C}, 56.39 ; \mathrm{H}, 3.49 ; \mathrm{N}, 10.96 \%$. IR (nujol, $\left.v_{\max } \mathrm{cm}^{-1}\right) 1515(\mathrm{~m}), 1427(\mathrm{~m}), 1310(\mathrm{~m}), 1283(\mathrm{~s}), 1206$ (m), 1108 (w), 1070 (w), 848 (s), 756 (s), 716 (s), 685 (s), 671 (s).

\subsection{Reaction of $\mathrm{Pd}_{2}(\mathrm{dba})_{3} \cdot \mathrm{CHCl}_{3}$ with $\mathrm{PhNO}$}

1,10-Phenanthroline $(105 \mathrm{mg}, 0.58 \mathrm{mmol})$ was added to a suspension of $\mathrm{Pd}_{2}(\mathrm{dba})_{3} \mathrm{CHCl}_{3}(200 \mathrm{mg}, 0.19$ $\mathrm{mmol})$ in degassed acetone $(50 \mathrm{ml})$. The resulting purple suspension was stirred at r.t. for $3 \mathrm{~h}$ during which time the mixture turned yellow and then PhNO (207 $\mathrm{mg}, 1.9 \mathrm{mmol}$ ) was added. The resulting red suspension was stirred at r.t. for $24 \mathrm{~h}$ to yield a green microcrystalline solid that was collected by filtration, washed with $\mathrm{Et}_{2} \mathrm{O}(10 \mathrm{ml})$, to eliminate the excess $\mathrm{PhNO}$, and dried in vacuo (63\%). The elemental analysis and spectroscopic data are in accord with those reported in Section 4.2.

\subsection{Preparation of $\left[\mathrm{Pd}(\text { phen })\left(\mathrm{C}_{3} \mathrm{H}_{5} \mathrm{O}\right)\right]_{2} \cdot \mathrm{CHCl}_{3} 2$}

1,10-Phenanthroline $(96 \mathrm{mg}, 0.53 \mathrm{mmol}$ ) was added to a suspension of $\mathrm{Pd}_{2}(\mathrm{dba})_{3} \cdot \mathrm{CHCl}_{3}(250 \mathrm{mg}, 0.24$ $\mathrm{mmol})$ in degassed acetone $(30 \mathrm{ml})$. The purple suspension was stirred at r.t. for $3 \mathrm{~h}$ during which time the mixture turned yellow and then $\mathrm{Bu}^{t} \mathrm{NO}(106 \mathrm{mg}, 0.60$ mmol) was added. The suspension was stirred at r.t. for $24 \mathrm{~h}$, then the solvent was evaporated to dryness and $\mathrm{CH}_{2} \mathrm{Cl}_{2}(40 \mathrm{ml})$ was added to the residue. The resulting yellow solution was filtered through celite to remove a trace amount of palladium black, evaporated to dryness and the yellow residue washed with $\mathrm{Et}_{2} \mathrm{O}(15 \mathrm{ml})$ to eliminated dibenzylidene acetone. The yellow solid was collected by filtration and dried in vacuo (67\%). Found $\mathrm{C}, 46.53 ; \mathrm{H}, 3.31 ; \mathrm{N}, 6.84\left[\mathrm{C}_{31} \mathrm{H}_{27} \mathrm{Cl}_{3} \mathrm{~N}_{4} \mathrm{O}_{2} \mathrm{Pd}_{2}\right]$ requires $\mathrm{C}, 46.27 ; \mathrm{H}, 3.38 ; \mathrm{N}, 6.97 \%$. ${ }^{1} \mathrm{H}-\mathrm{NMR}\left(\mathrm{CDCl}_{3}, 300\right.$ MHz, $298 \mathrm{~K}) \delta$, ppm: 9.75 (d, 2H, $J=5.6 \mathrm{~Hz}$ ); 9.45 (d,
$2 \mathrm{H}, J=5.1 \mathrm{~Hz}) ; 8.45(\mathrm{~m}, 4 \mathrm{H}) ; 7.96(\mathrm{~s}, 4 \mathrm{H}) ; 7.88(\mathrm{~m}$, $4 \mathrm{H}) ; 3.11(\mathrm{~s}, 4 \mathrm{H}) ; 2.44(\mathrm{~s}, 6 \mathrm{H}) .{ }^{13} \mathrm{C}-\mathrm{NMR}\left(\mathrm{CDCl}_{3}, 75\right.$ $\mathrm{MHz}, 298 \mathrm{~K}) \delta$, ppm: $214.1(\mathrm{CO}), 152.6(\mathrm{CH}), 149.8$ $(\mathrm{CH}), 138.3(\mathrm{CH}), 138.2(\mathrm{CH}), 130.3(\mathrm{C}), 129.9(\mathrm{C})$, $127.6(\mathrm{CH}), 127.5(\mathrm{CH}), 126(\mathrm{CH}), 125.5(\mathrm{CH}), 31$ $\left(\mathrm{CH}_{3}\right), 25.6\left(\mathrm{CH}_{2}\right)$. IR (nujol, $\left.v_{\max } \mathrm{cm}^{-1}\right) 1633$ (s) $(\mathrm{C}=\mathrm{O}), 1622$ (s) $(\mathrm{C}=\mathrm{O}), 1513(\mathrm{~m}), 1377(\mathrm{~m}), 1232$ (m), $836(\mathrm{~m}), 714(\mathrm{~s})$.

\subsection{Preparation of $\mathrm{Pd}($ phen $)\left\{\mathrm{C}(\mathrm{O}) \mathrm{OCH}_{3}\right\}_{2} 3$}

Complex 1 (100 mg, $0.11 \mathrm{mmol}$ ) was suspended in $\mathrm{CH}_{3} \mathrm{OH}(10 \mathrm{ml})$ and the resulting green suspension was placed in a glass liner inside an autoclave. The autoclave was frozen at dry ice temperature, evacuated and filled with dinitrogen three times, then $\mathrm{CO}$ (30 bar) was added at r.t., and the autoclave was heated at $80^{\circ} \mathrm{C}$ for $4 \mathrm{~h}$. The reaction mixture was filtered to eliminate a small quantity of metallic palladium and stored in a refrigerator for $24 \mathrm{~h}$. The precipitated yellow solid was collected by filtration and dried in vacuo (28\%). Recrystallisation from $\mathrm{CH}_{3} \mathrm{OH}$ gave crystals suitable for X-ray analysis. The data are in agreement with those reported in the literature [16]. The organic products were identified and quantified by GC-MS and GC analyses.

\subsection{Reaction of $\mathrm{Pd}($ phen $)\left\{\mathrm{C}(\mathrm{O}) \mathrm{OCH}_{3}\right\}_{2} 3$ with $\mathrm{PhNH}_{2}$}

$\mathrm{PhNH}_{2}(0.045 \mathrm{ml}, 0.5 \mathrm{mmol})$ was added to a suspension of $\mathrm{Pd}(\mathrm{phen})\left\{\mathrm{C}(\mathrm{O}) \mathrm{OCH}_{3}\right\}_{2} 3(10 \mathrm{mg}, 0.025 \mathrm{mmol})$ in methanol $(7 \mathrm{ml})$ under $\mathrm{CO}$ atmosphere $(1 \mathrm{bar})$ and at r.t. Palladium black formation started immediately and the suspension was stirred at r.t. for $12 \mathrm{~h}$. The resulting suspension was analysed by GC and HPLC analysis and the organic products observed were $\mathrm{PhN}$ $\mathrm{HCONHPh}$ and $\mathrm{PhNHCOOCH}_{3}$ in a 95:5 ratio.

\subsection{Catalytic reduction and carbonylation of nitrobenzene to methyl phenylcarbamate}

The experimental procedure to perform the catalytic reactions was identical to that previously described [24] using the following reagents amounts: $\mathrm{Pd}($ phen $)\left\{\mathrm{C}(\mathrm{O}) \mathrm{OCH}_{3}\right\}_{2} \quad 3$ or $\left[\mathrm{Pd}(\text { phen })_{2}\right]\left(\mathrm{BF}_{4}\right)_{2} \quad[20]$

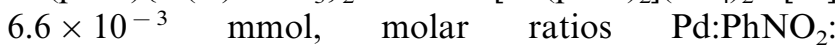
$\mathrm{PhNH}_{2}$ :phen:benzoic acid $=1: 2500: 66.6: 33.3: 227$. The reactions were run in methanol $(15 \mathrm{ml})+2,2^{\prime}$ dimethoxypropane $(0.5 \mathrm{ml})$ at $170^{\circ} \mathrm{C}$, under 60 bar $\mathrm{CO}$ for $1 \mathrm{~h}$. The products were analysed by gas chromatography.

\subsection{Crystal structure of $\mathrm{Pd}($ phen $)\left\{\mathrm{C}(\mathrm{O}) \mathrm{OCH}_{3}\right\}_{2} 3$}

Crystal data for 3: yellow prismatic crystal $0.08 \times$ $0.10 \times 0.18 \mathrm{~mm}^{3}, \mathrm{C}_{16} \mathrm{H}_{14} \mathrm{~N}_{2} \mathrm{O}_{4} \mathrm{Pd}, M=404.70$, graphitemonochromatized $\mathrm{Mo}-\mathrm{K}_{\alpha}$ radiation $(\lambda=0.71073 \AA)$, 
orthorhombic, space group Pbca (No. 61), $a=8.048(8)$, $b=16.264(6), c=22.816(12) \AA, U=2986(4) \AA^{3}, Z=8$, $\mu=12.5 \mathrm{~cm}^{-1}, T=293(1) \mathrm{K}$. A total of 3082 intensity data were collected on an Enraf-Nonius CAD-4 diffractometer (2612 unique, $R_{\text {int }}=0.018$ ), up to $2 \theta=50^{\circ}$ using an $\omega-\theta$ scan. Lorentz, polarization, decay (21\%) and an empirical absorption correction [25] were applied to the data. Scattering factors for all the atomic species and anomalous dispersions corrections for scattering factors of non-hydrogen atoms were taken from Ref. [26]. The structure was solved by Patterson and Fourier methods and refined by full-matrix leastsquares minimizing the function $\Sigma w\left(\left|F_{\mathrm{o}}\right|-k\left|F_{\mathrm{c}}\right|\right)^{2}$. An anisotropic thermal parameter was assigned to all the non-hydrogen atoms, whereas the hydrogen atoms were introduced in the structure model but not refined. Final $R=0.032$ and $R_{\mathrm{w}}=0.038$ for 1511 observed reflections having $I>3 \sigma(I)$. All the calculations were performed using the Personal SDP Structure Determination Package [27]. Crystallographic data for the structural analysis has been deposited with the Cambridge Crystallographic Data Centre, CCDC No. 115336 for compound $\mathbf{3}$.

\section{Acknowledgements}

The authors would like to thank Dr Laura Santagostini for help in recording and discussing EPR spectra and Dr Chiara Cazzaniga for performing the catalytic reactions. The authors also thank MURST (EX 40\%) for financial support.

\section{References}

[1] S. Cenini, F. Ragaini, Catalytic Reductive Carbonylation of Organic Nitro Compounds, Kluwer, Dordrecht, The Netherlands, 1997.

[2] (a) S. Cenini, F. Ragaini, M. Pizzotti, F. Porta, G. Mestroni, E. Alessio, J. Mol. Catal. 64 (1991) 179. (b) E. Drent, Pure \& Appl. Chem. 62 (1990) 661. (c) R. Santi, A.M. Romano, P. Panella, C. Santini, J. Mol. Catal. A 127 (1997) 95. (d) P. Wehman, P.C.J. Kamer, P.W.N.M. van Leeuwen, J. Chem. Soc. Chem. Commun. (1996) 217. (e) P. Wehman, V.E. Kaasjager, W.G.J. de Lange, F. Hartl, P.C.J. Kamer, P.W.N.M. van Leeuwen, J. Fraanje, K. Goubitz, Organometallics 14 (1995) 3751.

[3] P. Leconte, F. Metz, A. Mortreux, J.A. Osborn, F. Paul, F. Petit, A. Pillot, J. Chem. Soc., Chem. Commun. (1990) 1616.

[4] (a) A. Sessanta o Santi, B. Milani, G. Mestroni, E. Zangrando, L. Randaccio, J. Organomet. Chem. 545 (1997) 89. (b) N. Masciocchi, F. Ragaini, S. Cenini, A. Sironi, Organometallics 17
(1998) 1052. (c) F. Paul, J. Fischer, P. Ochsenbein, J.A. Osborn, Organometallics 17 (1998) 2199.

[5] (a) S.J. Skoog, J.P. Campbell, W.L. Gladfelter, Organometallics 13 (1994) 4137. (b) S.J. Skoog, W.L. Gladfelter, J. Am. Chem. Soc. 119 (1997) 11049.

[6] B. Milani, A. Anzilutti, L. Vicentini, A. Sessanta o Santi, E. Zangrando, S. Geremia, G. Mestroni, Organometallics 16 (1997) 5064 .

[7] T. Ukai, H. Kawazura, Y. Ishii, J.J. Bonnet, J.A. Ibers, J. Organomet. Chem. 65 (1974) 253.

[8] (a) M. Cameron, B.G. Gowenlock, R.V Parish,. G. Vasapollo, J. Organomet. Chem. 482 (1994) 227. (b) M.J. Barrow, O.S. Mills, J. Chem. Soc. (A) (1971) 864. (b) G. Vasapollo, C.F. Nobile, P. Giannoccaro, F. Allegretta, J. Organomet. Chem. 227 (1984) 417. (c) S. Otsuka, Y Aotani, Y. Tatsuno, T. Yoshida, Inorg. Chem. 15 (1976) 656. (d) G. Vasapollo, P. Giannoccaro, C.F. Nobile, F. Allegretta, J. Organomet. Chem. 270 (1984) 109. (e) M. Pizzotti, F. Porta, S. Cenini, F. Demartin, N. Maschiocchi, J. Organomet. Chem. 330 (1987) 265.

[9] W. Kaim, Coord. Chem. Rev. 76 (1987) 187.

[10] (a) S.K. Tyrlik, A. Rockenbauer, J. Chem. Soc. Chem. Commun. (1985) 1080. (b) A. Klein, S. Hasenzahl, W. Kaim, J. Chem, Soc. Perkin Trans. 2 (1997) 2573.

[11] (a) F. Ragaini, S. Cenini, F. Demartin, Organometallics 13 (1994) 1178. (b) P.-H. Liu, H.-Y. Liao, C.-H. Cheng, J. Chem. Soc. Chem. Commun. (1995) 2441.

[12] S.J. Sherlock, D.C. Boyd, B. Moasser, W.L Gladfelter, Inorg. Chem. 30 (1991) 3626.

[13] B.C. Hamann, J.F. Hartwig, J. Am. Chem. Soc. 119 (1997) 12382 .

[14] (a) P. Zuman, B. Shah, Chem. Rev. 94 (1994) 1621. (b) I.R. Bellobono, P.L. Beltrame, B. Marcandalli, A. Fumagalli, M. Trincheri, J. Chem. Soc. Perkin Trans. 2 (1977) 1989.

[15] G.D. Smith, B.E. Hanson, J.S. Merola, F. Waller, Organometallics 12 (1993) 568.

[16] R. Santi, A.M. Romano, R. Garrone, R. Millini, J. Organomet. Chem. 566 (1998) 37.

[17] J.D. Gargulak, A.J. Berry, M.D. Noirot, W.L. Gladfelter, J. Am. Chem. Soc. 114 (1992) 8933.

[18] J.D. Gargulak, W.L. Gladfelter, J. Am. Chem. Soc. 116 (1994) 3792.

[19] F. Ragaini, S. Cenini, 11th International Symposium on Homogeneous Catalysis (ISHC XI), St Andrews, Scotland, 1998.

[20] A. Bontempi, E. Alessio, G. Chanos, G. Mestroni, J. Mol. Catal. 42 (1987) 67.

[21] P. Wehman, L. Borst, P.C.J. Kamer, P.W.N.M. van Leeuwen, J. Mol. Catal. A 112 (1996) 23.

[22] (a) P. Veya, C. Floriani, A. Chiesi-Villa, C. Guastini, Organometallics 12 (1993) 253. (b) P. Veya, C. Floriani, A. Chiesi-Villa, C. Rizzoli, Organometallics 12 (1993) 4899.

[23] J. Andrieu, P. Braunstein, M. Drillon, Y. Dusausoy, F. Ingold, P. Rabu, A. Tiripicchio, F. Ugozzoli, Inorg. Chem. 35 (1996) 5986.

[24] F. Ragaini, S. Tollari, S. Cenini, E. Bettetini, J. Mol. Catal. A 111 (1996) 91.

[25] A.C. North, D.C. Phillips, F.S. Mathews, Acta Crystallogr. A24 (1968) 351.

[26] International Tables for X-ray Crystallography, The Kynoch Press, Birmingham, UK, vol. IV, 1974.

[27] B.A. Frenz, Computing In Physics 2(3) (1988) 42; B.A. Frenz, Crystallographic Computing 5, vol. 11, Oxford University Press, Oxford, UK, 1991, p. 126. 